\title{
A conformação urbana de Pimenta Bueno-RO: uma análise sobre a evolução urbana da cidade ${ }^{1}$
}

\begin{abstract}
Resumo
O presente trabalho tem como objetivo fazer um estudo sobre a conformação urbana de Pimenta Bueno, Rondônia, evidenciando os principais fatores históricos que guiaram o crescimento da cidade e sua evolução urbana. Dentre eles, destaca-se a implantação do Posto Telegráfico, que se caracterizou como um importante fator para o desenvolvimento do até então povoado. Em um segundo momento observa-se uma política nacional de integração do território, que se desdobra na construção da BR-364, bem como o Plano de Colonização promovido pelo Instituto Nacional de Colonização e Reforma Agrária (INCRA). Vê-se ainda que, a partir da década de 1980, o crescimento é balizado pela criação do distrito industrial e, também, por investimentos em habitação popular. Fica notório que o acelerado processo de crescimento da cidade trouxe problemas, sendo explicitado no urbano por meio da segregação espacial.
\end{abstract}

Palavras-chave: Pimenta Bueno; BR-364; Colonização; Indústria e habitação.
Áurea Dayse Cosmo da Silva

Mestranda em Planejamento

Urbano e Regional na

Universidade Federal de Viçosa -

UFV - MG.

Brasil

aurea.silva@ufv.br

\section{Regina Esteves Lustoza}

Doutora em Geografia pela

Universidade Federal Fluminense;

Professora da UFV - MG.

Brasil

rlustoza@ufv.br

\section{Teresa Cristina de Almeida Faria \\ Doutora em Planejamento \\ Urbano e Regional pela Univ. \\ Federal do Rio de Janeiro UFRJ; \\ Professora da UFV - MG. \\ Brasil \\ teresa.faria@ufv.br}

\footnotetext{
${ }^{1}$ Projeto de pesquisa Formação e Transformação: A Produção do Espaço Interurbano da Microrregião de Vilhena-Rondônia, com apoio da CAPES.
} 


\title{
The forming urban of Pimenta Bueno-RO: an analysis of the urban evolution of the city
}

\begin{abstract}
The present work aims to make a study on urban conformation of PimentaBueno, Rondônia, highlighting the major historical factors that guided the growth of the city and its urban evolution. Among them, we highlight the implementation of the Telegraph Station, which was characterized as an important factor for the development of the previously populated. In a second step we observe a national integration policy of the territory, which unfolds on the construction of the BR364 and the Colonization Plan promoted by INCRA. It is seen even from the 80 's growth is marked by the creation of the industrial district as well as investments in social housing. Is well known that the accelerated growth of the city brought their problems, being explained by the urban spatial segregation.
\end{abstract}

Keywords: Pimenta Bueno; BR-364; Colonization; Industry and housing.

\section{Para citar este artigo:}

SILVA, Áurea Dayse Cosmo da; LUSTOZA, Regina Esteves; FARIA, Teresa Cristina de Almeida. A conformação urbana de Pimenta Bueno-RO: uma análise sobre a evolução urbana da cidade. Revista PerCursos. Florianópolis, v. 16, n.30, p. 58-73. jan./abr. 2015.

DOI: $\mathbf{1 0 . 5 9 6 5 / 1 9 8 4 7 2 4 6 1 6 3 0 2 0 1 5 0 5 8}$

http://dx.doi.org/10.5965/1984724616302015058 


\section{Introdução}

Pimenta Bueno é uma cidade no interior de Rondônia, que se localiza ao sul do estado possuindo uma população de 33.822 habitantes e um território de $6258,64 \mathrm{~km}^{2}$. De acordo com Lorenzon(2002), as primeiras manifestações urbanas foram constatadas em 1926,àsmargens do Rio Barão de Melgaço, devido ao grande projeto de implantação da rede telegráfica de Marechal Rondon. Esse cenário se manteve até 1940,quando a economia era baseada na extração da borracha, no garimpo de diamantes, além das atividades do porto de embarcações, onde se localizava, também, o posto telegráfico.

Em 1960, esse até então vilarejo inicia um processo de expansão devido à abertura da BR-364, que foi feita pelo $5^{\circ}$ Batalhão de Engenharia e Construção.Esse processo se acentua em 1969 com a implantação do Projeto Integrado de Colonização feito pelo Instituto Nacional de Colonização e Reforma Agrária(INCRA), que tinha como objetivo principal promover o crescimento do até então território do Guaporé, que se torna Território Federal de Rondônia em 1956 (LORENZON, 2002).

Assim, antes mesmo da vila ser elevada àcondição de município, o seu crescimento foi conduzido em direção à BR-364, que naquele momento representava o vetor do "desenvolvimento" da região amazônica. Dessa forma, a vila se desenvolveu para a direção leste de seu território, que tinha a presença da Igreja Matriz Nossa Senhora de Fátima, a Escola Sandoval Meira, o Cartório do $1^{\circ}$ Ofício, além dos primeiros comércios que também se instalaram na Rua Fernão Dias, que até então era a principal do vilarejo. Tal vila foi elevada à categoria de município em 1977, recebendo o nome de Pimenta Bueno em homenagem àFrancisco Antônio Pimenta Bueno, chefe da equipe de implantação do projeto de Marechal Rondon (LORENZON, 2002).

A implantação da BR-364 se consolidou como um importante fator de cristalização da malha urbana da cidade, pois promoveu uma divisão no território do município, levando, no final da década de 1970, os primeiros investimentos para o "lado de lá" da rodovia,ou seja, para a região nordeste da cidade. O foco principal dos investidores concentrou-se em habitação, com o objetivo de absover os migrantes vindos predominantemente das regiões Nordeste e Sudeste.Após esses investimentos em 
habitação, instala-setambém nessa região da cidade o prédio da Prefeitura Municipal em 1986. Esses foram fatores preponderantes para o rápido crescimento dessa região da cidade, que se consolidou como o centro comercial.

A partir da década de 1980,a malha urbana de Pimenta Bueno sedesenvolve em direção à região sudeste da cidade. Esse fato éguiado pela implantação do Distrito Industrial no município em 1982, seguido pelo investimento do Banco Nacional de Habitação no final dessa mesma década. (LORENZON, 2002)

\section{A produção das cidades}

De acordo com Spósito(2000), o capitalismo atribuiu uma grande valorização à cidade por meio de um processo de urbanização expressivo e extenso,emnível mundial. É por meio do renascimentourbano que há revitalização do comércio enquanto atividade ecônomica urbana, fator determinante para a estruturação do modo de produção capitalista. É dessa maneira que ocorre o fortalecimento da burguesia comercial, proporcional ao crescimento de sua riqueza, e é ainda nesse contexto que muitas cidades obtiveram sua autonomia. Com o seu desenvolvimento, o capitalismo propicia uma ampliação no processo de urbanização, dando à cidade um caráter produtivo de multiplicidade funcional.

Carlos (1991) mostra que o homem passa a ser julgado por sua capacidade de possuir as coisas, um valor imposto pela sociedade urbana. E é nesse contexto que a cidade se produz, por meio de um padrão arquitetônico que segrega, separa e expulsa. É ainda colocado pela autora que o uso diferenciado da cidade demostra que esse espaço se constrói e se reproduz de forma desigual e contraditória, sendo a desigualdade espacial fruto da desigualdade social. Assim, a cidade se define como

[...]a expressão mais contundente do processo de produção da humanidade sob a égide das relações desencadeadas pela formação econômica e social capitalista. A cidade é um modo de viver, pensar, mas também de sentir. $O$ modo de vida urbano produz ideias, 
comportamentos, valores, conhecimentos, formas de lazer, e também uma cultura (CARLOS, 1991, p. 25-26).

O espaço urbano apresenta a exclusão social por segregação, que pode ser facilmente vista emdiferentes padrões das edificações em diferentes áreas. No caso de habitações, vemos essa diferenciação a partir darenda dos moradores, porém existem outros fatores, como a especulação imobiliária, que acentuam essa questão. Observa-se que a segregação é impressa na arquitetura e no urbanismo de uma cidade, todavia é importante ressaltar que esse é um problema que se inicia com o agravamento das questões sociais, que dificultam o acesso de parte da população ao setor de serviços (LOPES JUNIOR, 2009).

A desigualdade social está sendo vista em quase todos os lugares, porém em escalas diferentes. O sistema capitalista coloca em evidência questões como o desemprego, pobreza e marginalidade. No entanto, conformeé abordado por Lopes Junior(2009), a desigualdade não é um fenômeno da sociedade neoliberal, ela existe desde os tempos remotos em que os chefes guerreiros tinham acesso exclusivo a determinados tipos de bens.

No que diz respeito a essa questão, nota-se a existência e manutenção de uma estratificação urbana, sendo que a segregação é uma de suas formalizaçõos ou manifestações. Isso pode ser identificado na localização das novas centralidades e nas características socioeconômicas daquelas pessoas que frequentam os diferentes lugares, como shopping centersou a rua comercial do centro tradicional de uma cidade (LOPES JUNIOR, 2009).

Num primeiro sentido, entenderemos por segregação urbana, a tendência à organização do espaço em zonas de forte homogeneidade social interna e com intensa disparidade social entre elas, sendo esta disparidade compreendida não só em termos de diferença, como também de hierarquia (CASTELLS, 1983, p.210). 
Villaça (1998) expõe que a segregação espacial surge a partir da luta de classes na apropriação do espaço construído, fazendo com que as vantagens locacionais caracterizem-na. Dessa forma, as localizações que acabam sendo disputadas no espaço urbano, por motivos de produção e consumo, são responsáveis pela segregação sócioespacial.

Assim, a partir da lógica capitalista, vemos que a distribuição de renda e o acúmulo de capital caracterizam o sistema, e isso gera suas consequências no espaço urbano, já que é possível ver uma cidadehierarquizada, ainda que tenha sua homogeneidade social interna.

Em Pimenta Bueno vemos que há a formalização da segregação. Num primeiro momento, podemos analisá-la a partir dos diferentes padrões das edificações presentes na cidade. Observa-se que no Bairro Jardim das Oliveiras, região embrionária da cidade, as casas são predominantemente de madeira. O uso desse material se remete ao processo histórico de formação da região, fortemente embasado na extração madeireira. Porém, atualmente, essas edificaçõessão ocupadas principalmente por uma população de baixa renda, que não tem condições de dar a manutenção necessária ao material, estereotipando um baixo padrão das construções.

O Bairro Pioneiros, impulsionado pela passagem da BR-364 no território da cidade, é marcado por um centro comercial forte.Vemos que as casas possuem um padrão mais elevado, que pode ser justificado pelo fato dessa ser a região com maior infraestrutura da cidade. E a habitação nos bairros mais recentes se apresenta num padrão baixo, devido à presença de conjuntos habitacionais populares que guiou o proletariado para essa região. 


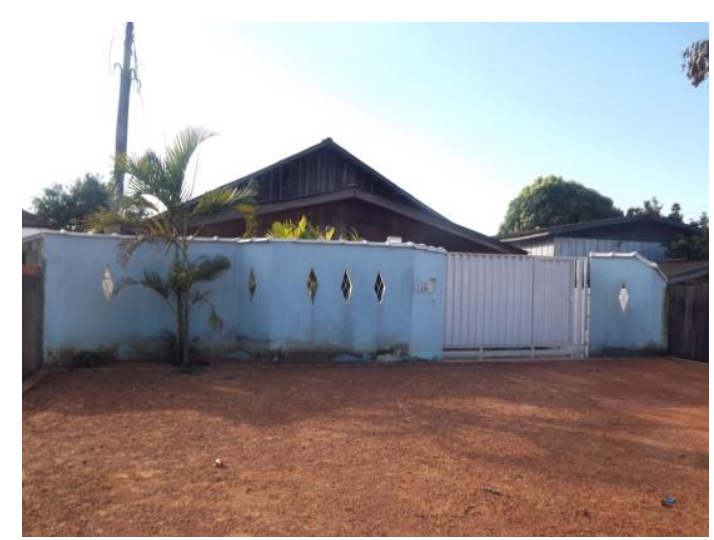

Figura 1 - Residência no Bairro Jardim das Oliveiras, 2013

Fonte: Acervo da pesquisa, (2013).

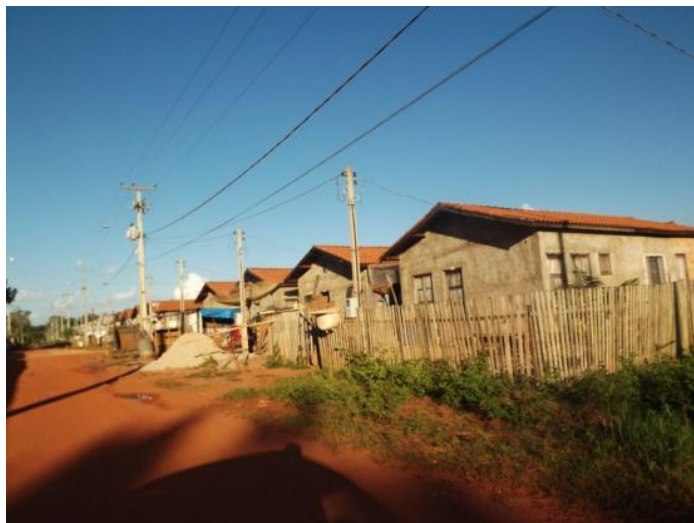

Figura 2 - Residências no Bairro Encontro das Águas, 2013

Fonte: Acervo da pesquisa, (2013).

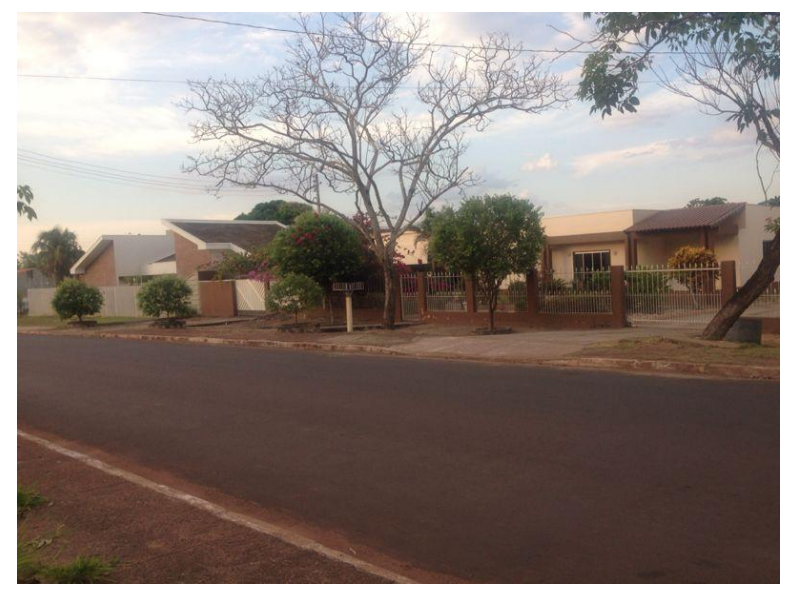

Figura 3 - Residências no Bairro Pioneiros, 2013 Fonte: Acervo da pesquisa, (2013).

\section{Da rede telegráfica ao distrito industrial:}

\section{A rede telegráfica}

De acordo com Lorenzon(2002), a ideia da implantação da linha telegráfica surgiu no governo do Presidente Rodrigues Alves, como uma necessidade no contexto da construção da Estrada de Ferro Madeira Mamoré em 1905, pois nesse momento a comunicação necessitava de uma dinamização. Dessa forma, o projeto tinha como objetivo fazer a interligação do Rio de Janeiro até Santo Antônio do Madeira-RO.

No Império de D. Pedro II houve a implantação de uma linha telegráfica de FrancaSP até Cuiabá-MT. Isso favoreceu a implantação do projeto devido ao encurtamento da 
linha a ser implantada. Assim, já no mandato de Afonso Pena, Marechal Cândido da Silva Rondon foi nomeado, devido a sua experiência na construção e manutenção de linhas telegráficas no oeste do Brasil, para coordenar a Comissão das Linhas Telegráficas e Estratégicas do Mato Grosso ao Amazonas -Comissão Rondon -que foi criada pelo Ministério da Guerra (LORENZON, 2002).

Os trabalhos começaram em Cuiabá-MT e tinham como objetivo inicial chegar até Santo Antônio do Madeira. Assim, as atividades da Comissão se dividiram em duas fases:

\begin{tabular}{|c|c|}
\hline $\begin{array}{l}1^{a} \text { Fase } \\
1907-1909\end{array}$ & Reconhecimento e Exploração \\
\hline $\begin{array}{l}2^{a} \text { Fase } \\
1910-1920\end{array}$ & Implantação, Manutenção e Ampliação \\
\hline
\end{tabular}

A implantação da Rede Telegráfica permitiu a fixação de vários núcleos populacionais em suas margens, tendo maior afirmação as regiões no entorno das estações, como é caso das cidades rondonienses de Pimenta Bueno, Vilhena e Jaru, pois demandavam funcionários para seu funcionamento, que se instalavam com suas famílias nessas regiões (LORENZON,2002).

\section{A descoberta}

A cidade surgiu com o descobrimento do Rio Apidiá e posterior instalação da rede telegráfica àsmargens do Rio Barão de Melgaço que ligaria o Mato Grosso ao Amazonas.Com a rede, Marechal Rondon nomeou Durval Lebre como telegrafista e guarda-fios e a estação telegráfica recebeu o nome de Pimenta Bueno, núcleo embrionário da futura cidade em homenagem ao Dr. José Antônio Pimenta Bueno, que era presidente da Província de Mato Grosso (1835-1836). A rede telegráfica foi inaugurada em 15 de setembro de 1914 (LORENZON, 2002). 


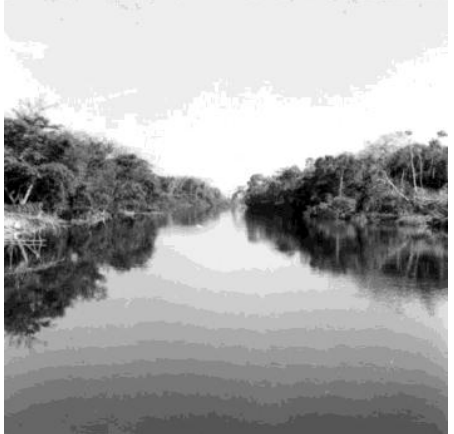

Figura 4 - Rio Barão de Melgaço, s/d Fonte: Prefeitura Municipal de Pimenta Bueno, (s/d).

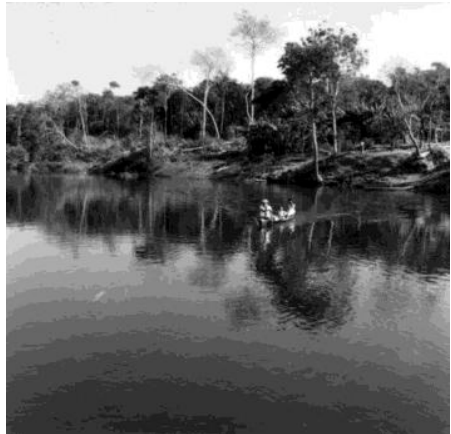

Figura 5 - Rio Barão de Melgaço, s/d Fonte: Prefeitura Municipal de Pimenta Bueno, (s/d).

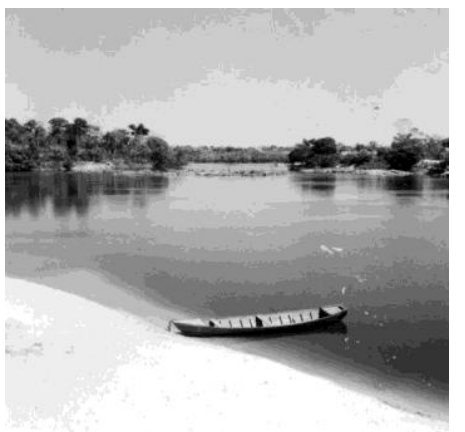

Figura 6 - Rio Apidiá, s/d Fonte: Prefeitura Municipal de Pimenta Bueno, (s/d).

\section{A BR-364}

A construção da BR-029 que atualmente é a BR-364, surgiu com necessidade da ligação da Região Norte aos demais centros do país, especialmente a Região Sul. De acordo com Lorenzon(2002), essa necessidade foi caracterizada pela viabilização da exploração de cassiterita, que tinha suas principais usinas de redução e refino localizadas em São Paulo, Minas Gerais e Manaus-AM e a principal consumidora de estanho era a Companhia Siderúrgica Nacional (CSN). Houve a tentativa de implantação de usinas em Porto Velho-RO, porém foi inviabilizado pela baixa capacidade energética da região naquele período, o que consequentemente elevava os custos.

Dessa forma, em março 1960, o presidente Juscelino Kubitschek criou a Comissão Especial de Construção da Rodovia Brasília-Acre, estabelecendo dezembro o prazo para o término da obra.

A importante obra, que esteve a cargo da Construtora Camargo Correia, veio a ser inaugurada pelo presidente Kubistchek, no dia 13 de janeiro de 1961. Oportunamente $05^{\circ}$ Batalhão de Engenharia de Construção, foi incumbido de concluir a obra, que se deu no ano de 1966 (LORENZON, 2002, p.76).

Apesar da rodovia não ter sido asfaltada de início, facilitou o trânsito em sua extensão. Além disso, exerceu uma importante função no desenvolvimento da 
agricultura e no processo migratório que surgiu com sua abertura.O período compreendido entre 1970 e 1984 é marcado por um abandono do governo, tornando-a quase intransitável(LORENZON, 2002).

Assim, ainda em 1984, o asfaltamento da BR-364 foi anunciado e concluído. Isso possibilitou para a região uma série de vantagens, já que o trânsito não era mais determinado pelo regime de chuvas. Entre as vantagens vê-se a facilidade no acesso a produtos industrializados devido à redução de custo no transporte, bem como a viabilização do escoamento dos produtos rondonienses.

A cidade de Pimenta Bueno, além dos benefícios diretos do asfaltamento da BR364, também sediou uma das bases da construtora Mendes Júnior, que era responsável pela execução do projeto. Dessa forma, a cidade recebeu, em 1983, um condomínio para abrigar a equipe de engenheiros e um conjunto habitacional para os funcionários da obra que vieram de fora. Isso movimentou a economia local, já que demandou infraestrutura básica e mão de obra.

\section{Plano de colonização: "integrar para não entregar"}

A colonização em Rondônia ganhou força com concretização da BR-364, em 1961, pois apesar da longa distância da região sul do país, nesse momento o acesso não era limitado aos períodos chuvosos. É importante lembrar que nessaépocao Brasil enfrentava a Ditadura Militar e a propaganda oficial caracterizou o governo de Emílio Garrastazu Médici (1969-1974) como o “milagre brasileiro". A economia vivia um momento de ascensão devido ao aumento da produção industrial e ao crescimento das exportações e isso levou àcaptação de empréstimos no exterior. Todavia, essa euforia econômica trouxe sérios problemas à nação brasileira, devido ao endividamento e ao aumento da concentração de renda/terra nas mãos de uma minoria (LORENZON, 2002).

Dessa forma, muitas pessoas enxergaram o "Eldorado Brasileiro"2 como uma oportunidade de melhorar a condição de vida, já que, segundo Lorenzon(2002), as

\footnotetext{
${ }^{2}$ De acordo com Lorenzon (2002), o Eldorado Brasileiro era a Região Norte, pois era promissora e representava a esperança de uma vida melhor para os migrantes.
} 
propagadas anunciavam a possibilidade de um rápido enriquecimento devido àdistribuição de terras e lotes na região. Todavia, devemos ultrapassar o nosso olhar para enxergar o real objetivo do governo com essa distribuição de terras, já que o "fantasma americano" possuía um grande interesse nessas terras que, até então,eram"terra de ninguém".

O INCRA foi o órgão responsável pelo Plano Integrado de Colonização (1969), porém sua estruturação ainda era limitada para as proporções que a colonização estava tomando. Em muitos casos a terra não doada a priori, de forma que as pessoas ocupavam a gleba, faziam suas benfeitorias e depois registravam no órgão a ocupação. Vale lembrar que a política exercida pelo INCRA era de incentivo ao desmatamento sob a pena de não poderem titular a propriedade. Assim,muitas madeiras nobrescomo o mogno e a cerejeira foram vendidas a preços baixíssimos quando não eram queimadas. (LORENZON, 2002)

Foi nesse contexto que Pimenta Bueno se afirmou como um núcleo urbano forte, levando o crescimento para outras regiões da cidade devido ao elevado número de migrantes para a cidade, bem como o desenvolvimento econômico às margens da $\mathrm{BR}-$ 364. Dessa forma, em 1977 o vilarejo foi elevado à condição de Município.

\section{A evolução da malha urbana}

A partir de uma análise da planta percebe-se que o traçado de Pimenta Bueno é regular, divido em quadras ortogonais. A partir do Mapa 1 é possível observar que os principais condicionantes do traçado urbano da cidade caracterizam-se pela passagem da BR-364 que faz uma divisão do território e pela rede hidrográfica, caracterizada pelos rios Apidiá e Barão de Melgaço. 


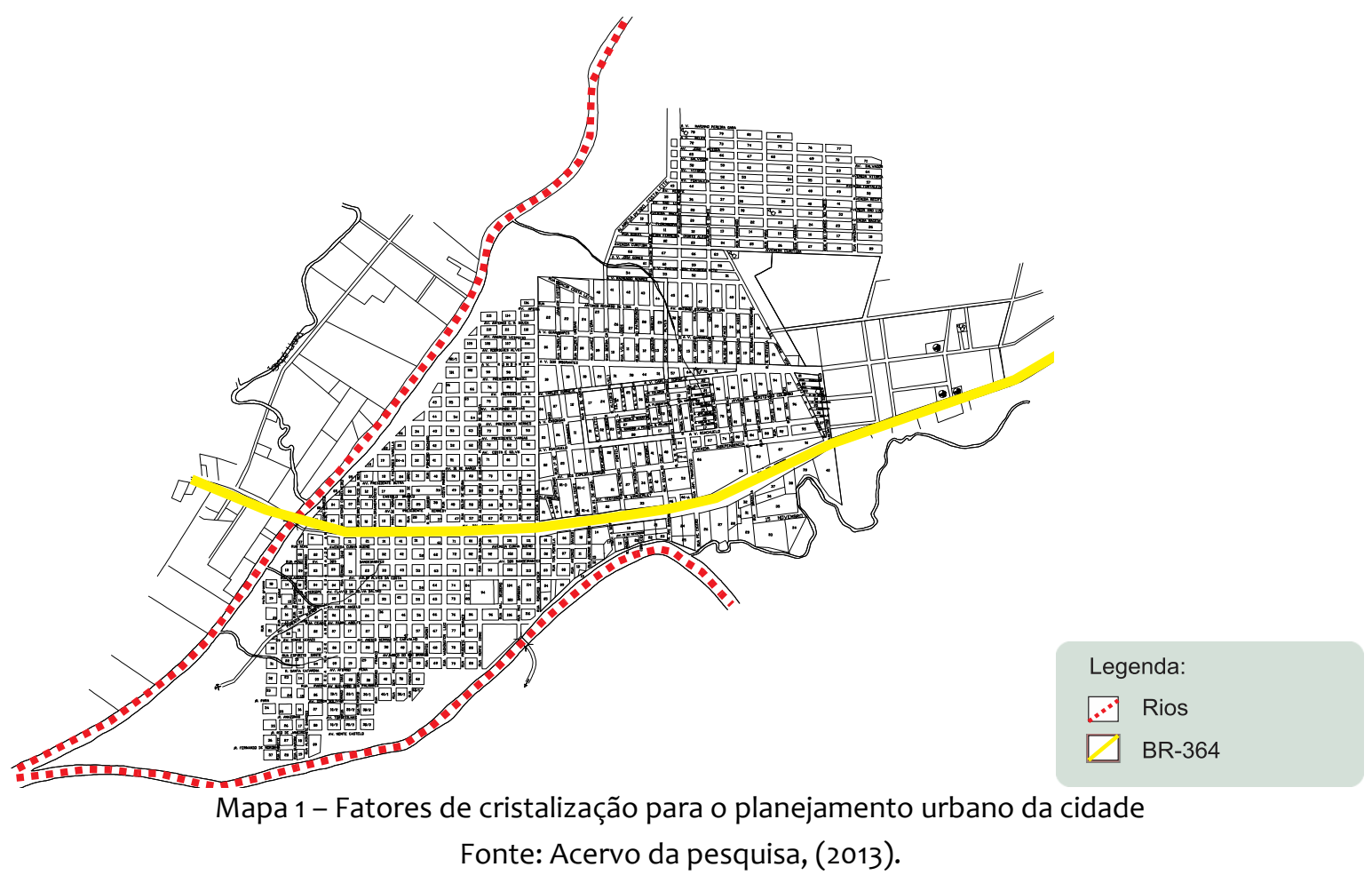

No primeiro momento, ou seja, no primeiro núcleo urbano, o ordenamento foi feito a partir do "saber popular"dos gestores locais e das pessoas que habitavam o vilarejo, todavia é possível observar uma regularidade no padrão das quadras. De acordo com dados da Prefeitura Municipal, o primeiro planejamento para cidade aconteceu em 1975, e foi projetado até onde conhecemos como o Bairro Vila Nova (Mapa 2). Esse traçado foi feito por uma equipe da Superintendência de Desenvolvimento do Centro Oeste (SUDECO), que ficou na cidade por 30 dias, fazendo os levantamentos e concebendo o traçado da cidade, ou seja, norteando para qual região deveria se desenvolver. O Setor Industrial e o Bairro Nova Pimenta vieram com a Gestão de Reginaldo Monteiro, em 1982, e esse planejamento foi feito por equipe técnica local. 


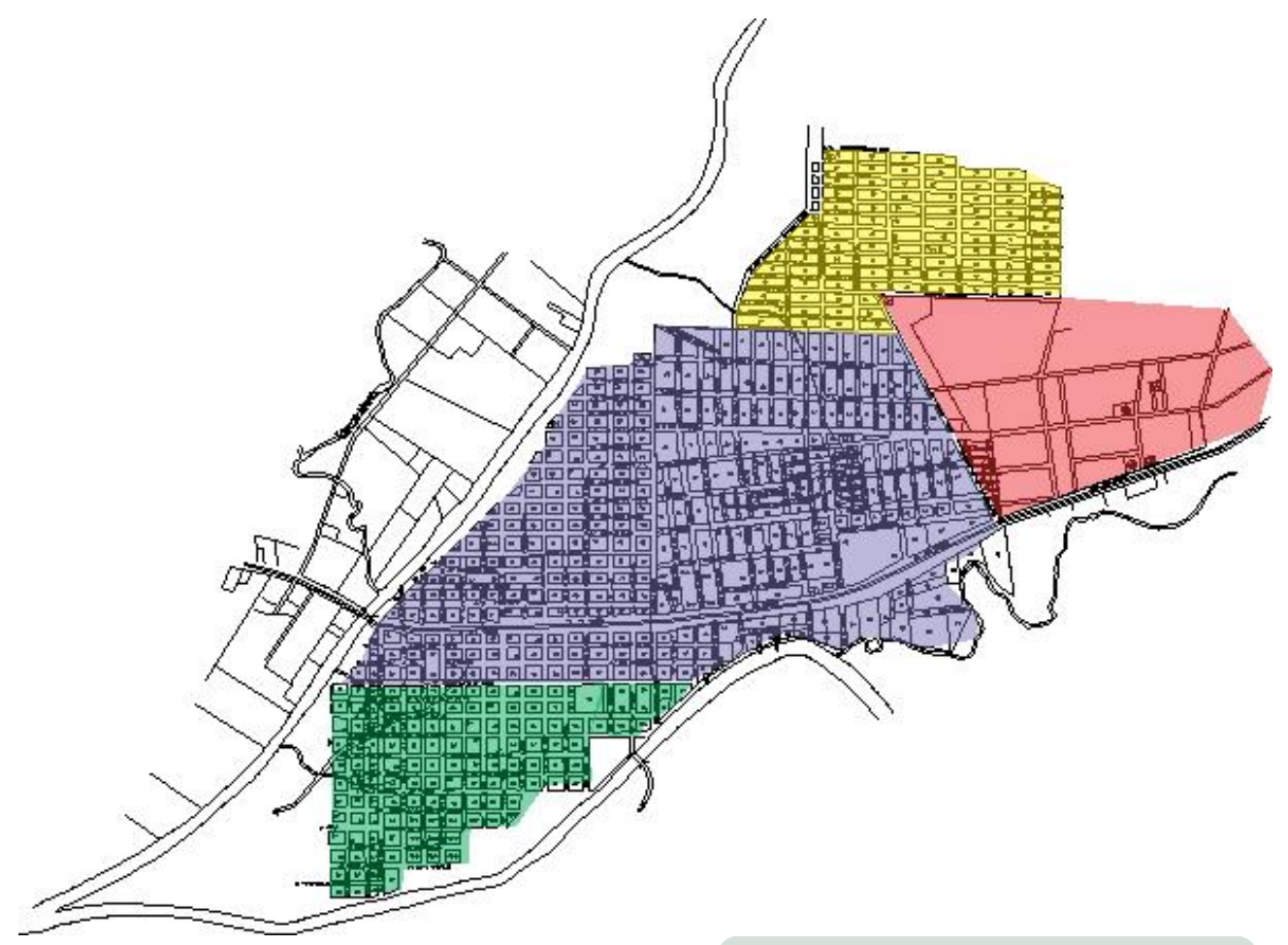

Legenda:

$\square$ 1ํo Ordenamento Urbano

$11^{\circ}$ Fase Planejamento Urbano

$\square 2^{2}$ Fase Planejamento Urbano (Bairro Nova Pimenta)

$2^{\mathrm{a}}$ Fase Planejamento Urbano (Setor Industrial)

Mapa 2 - Evolução da malha urbana

Fonte: Acervo da pesquisa, 2013.

O padrão das quadras mudou no decorrer da construção da cidade. Noinício do projeto, em 1975, a intenção era fazer quadras de 100mx100m e 100mx8om, mas o sistema viário estava ficando com muitas ruas, encarecendo a urbanização da cidade. Então, para minimizar esse problema, as quadras assumiram uma dimensão de 8omx18om (Mapa 3). No Bairro Nova Pimenta, que foi um planejamento posterior, vê-se que as quadras possuem uma dimensão diferente, $60 \mathrm{mx} 180 \mathrm{~m}$, assim como as quadras do setor industrial que tinham umadimensão fixa, mas se organizavam em tamanhos maiores para receber as indústrias. 


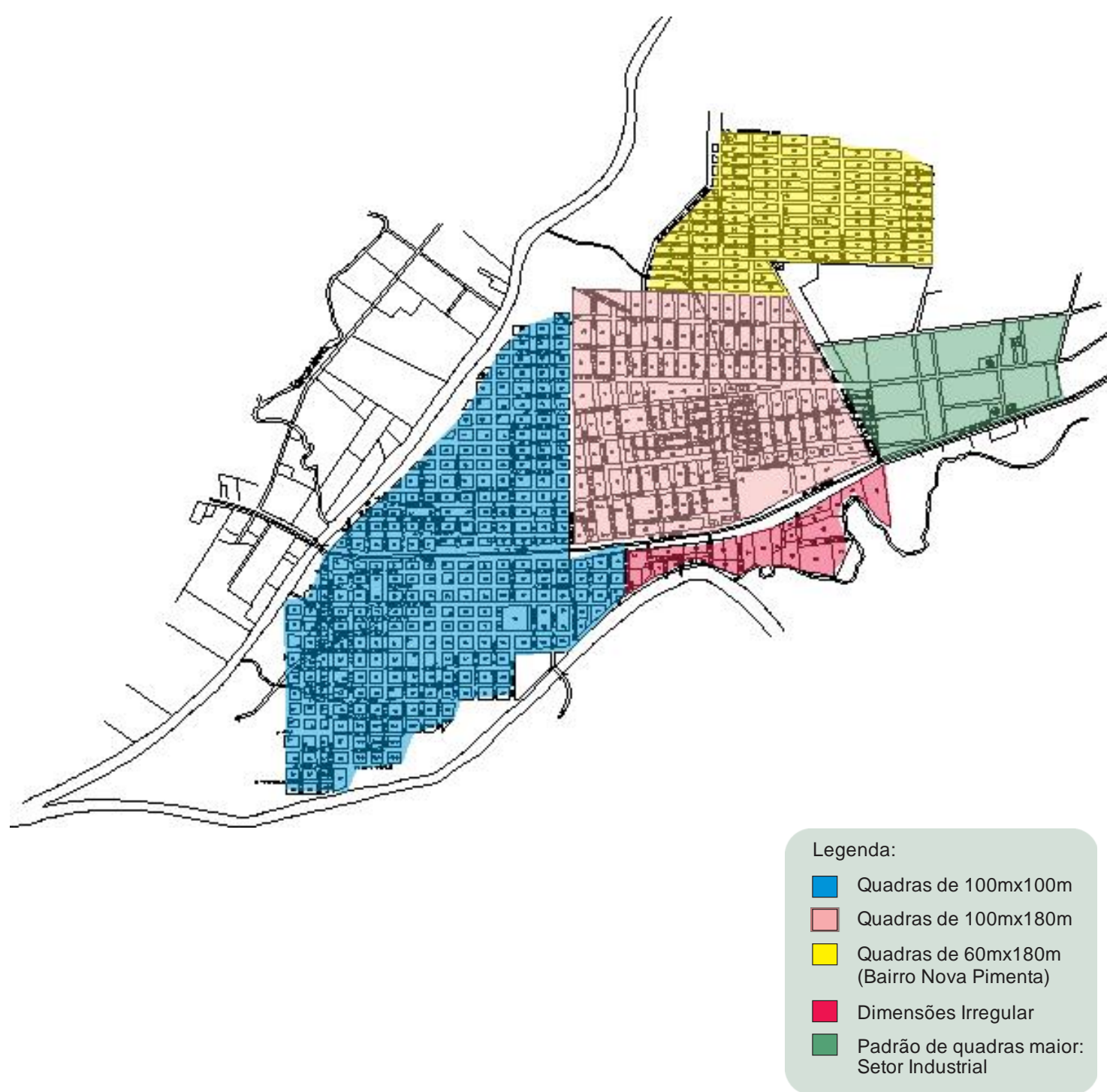

Fonte: Acervo da pesquisa, (2013).

Mapa 3 - Padrão das quadras

\section{Conclusões}

A conformação urbana de Pimenta Bueno é fortemente marcada pelo processo migratório para a região amazônica, iniciado a partir da década de 1970. A oportunidade de ter uma terra, bem como a necessidade do Estado Nacional ocupar a região, caracterizaram o cenário brasileiro naquele momento. É nesse contexto que Pimenta Bueno, assim como toda a região amazônica passaram a ter uma virtude econômica, a partir da valorização da terra, que propiciou o processo de urbanização. Este fato se deu 
de um modo muito acelarado, iniciado com a implantação do Posto Telegráfico e estimulado pela criação e execução da BR-364.

É possível observar que esse rápido crescimento urbano foi um impulsionador da segregação espacial na cidade. Isso é decorrente da ausência de um adequado planejamento de desenvolvimento para a região, que englobasse todas as variáveis desse processo.

Observou-se que o traçado da cidade reflete-se na produção de um espaço sem infraestrutura, que se iniciou a partir do empirismo dos pioneiros locais, seguido de “planejamento" feito por uma equipe técnica, porém isso não impediu a formação de uma cidade sem conexão. Outros fatores importantes são os preponderantes para esse traçado, que são constituídos pela rede fluvial, bem como a BR-364, que se inserem na malha urbana como fatores de cristalização, que não foram abordados adequadamente no planejamento, já que vemos uma cidade que enfrenta problemas com as cheias e dividida por uma rodovia.

\section{Bibliografia citada}

CARLOS, Ana Fani Alessandri. ACidade. São Paulo: Contextos,1991.

CARLOS, Ana Fani Alessandri (Org.) et al. A Produção do espaço urbano. São Paulo: Contextos, 2001.

CARLOS, Ana Fani Alessandri. A (Re)produção do espaço urbano. São Paulo: Ed.da Universidade de São Paulo, 2008.

CASTELLS, Manuel. A questão Urbana. 2ed. São Paulo: Paz e Terra, 2006.

LOPES JUNIOR, Wilson Martins; SANTOS, Regina Celia Bega dos. Novas centralidades na perspectiva da relação centro-periferia.Sociedade \& Natureza, Uberlândia, v. 21, n. 3, p. 351-359, dez. 2009.Disponível em:<http://www.seer.ufu.br/index.php/sociedade natureza/article/view/9616> Acesso em: 19 ago. 2013. 
LORENZON, A.R. Pimenta Bueno, um pouco de sua História. Edição. Pimenta Bueno-RO: Editora, 2002.

SPÓSITO, Maria Encarnação Beltrão. Capitalismo e Urbanização. 10 ed. São Paulo: Contextos, 2000.

VILLAÇA, Flávio. Espaço intra-urbano no Brasil. São Paulo: Lincoln Institute, 2001. 